\title{
Erratum to: Schizophrenia Patient or Spiritually Advanced Personality? A Qualitative Case Analysis
}

\author{
Hemant Bhargav • Aarti Jagannathan • Nagarathna Raghuram • \\ T. M. Srinivasan • Bangalore N. Gangadhar
}

Published online: 30 January 2015

(C) Springer Science+Business Media New York 2015

\section{Erratum to: J Relig Health DOI 10.1007/s10943-014-9994-0}

The below acknowledgement text was not submitted and hence not included in the original publication.

Acknowledgments We are thankful to Dr. K. Raghu, Consultant psychiatrist, Department of Psychiatry, Premier Specialty Center, Bangalore, India, for providing the basic concept behind this manuscript by assessing the above patient. He provided important inputs regarding the differentiating points between

The online version of the original article can be found under doi:10.1007/s10943-014-9994-0.

H. Bhargav $(\bowtie) \cdot$ A. Jagannathan · N. Raghuram

Division of Yoga and Life Sciences, Swami Vivekananda Yoga Anusandhana Samsthana (S-VYASA)

University, No. 19, Eknath Bhavan, Gavipuram Circle, Kempegowda Nagar,

Bangalore 560019, Karnataka, India

e-mail: hemant.bhargav1@gmail.com

A. Jagannathan

e-mail: jaganaarti@gmail.com

N. Raghuram

e-mail: rnagaratna@gmail.com

T. M. Srinivasan

Division of Yoga and Physical Sciences, Swami Vivekananda Yoga Anusandhana Samsthana

(S-VYASA) University, No. 19, Eknath Bhavan, Gavipuram Circle, Kempegowda Nagar,

Bangalore 560019, Karnataka, India

e-mail: tmsrini@gmail.com

B. N. Gangadhar

National Institute of Mental Health and Neurosciences (NIMHANS), Hosur Road, Hombegowda

Nagar, Bangalore 560029, Karnataka, India

e-mail: bng@nimhans.kar.nic.in 
spiritually advanced individual and schizophrenia patient during discussions. For this, he was originally supposed to have been one of the co-authors, but due to unforeseen circumstances this could not happen and hence this acknowledgement. 